Marquette University

e-Publications@Marquette

$1-1-2005$

Faktizität und Geschichtlichkeit als Konstituentien der Lebenswelt in Husserls Spätphilosophie

Sebastian Luft

Marquette University, sebastian.luft@marquette.edu

Published version. Phänomenologische Forschungen (2005): 13-40. Publisher Link. (C) 2005 Meiner. Used with permission. 
Sebastian Luft

\title{
Faktizität und Geschichtlichkeit als Konstituentien der Lebenswelt in Husserls Spätphilosophie
}

\begin{abstract}
In this paper I shall present two elements of Husserl's theory of the life-world, facticity and historicity, which are of exemplary importance for his late phenomenology as a whole. I compare these two notions to two axes upon which Husserl's phenomenology of the life-world becomes inscribed. Reconsidering and reconstructing Husserl's late thought under this viewpoint sheds new light on a notoriously enigmatic problem, i.e., the concept of the transcendental and its relation to the "mundane“ - to the world as constituted by transcendental consciousness. Drawing on unpublished manuscript material I claim, specifically, that the transcendental subject, in its „self-enworlding “ activity, as it were, „covers its tracks" so as to obscure the transcendental origin of the worldly ego. This self-obscuring is itself an eidetic law of transcendental consciousness. The ambiguity in the transcendental/mundane ego is thrown into relief through Husserl's analyses concerning the corporeal functioning of the lived-body. These considerations help further clarify Husserl's claim that the transcendental and the factical are „moments of one structure“, while also incorporating the problem of historicity.
\end{abstract}

\section{Einleitung}

Es ist unzweifelhaft, daß „Welt“ das Grundthema von Husserls später Phänomenologie ist. Welt wird bei Husserl - ausgehend von seinen früheren Analysen zur Dingwahrnehmung ab ca. 1905 und seiner Charakterisierung der „Welt der natürlichen Einstellung“ in den Ideen I von 1913 - zunehmend weiter gefaßt und schließlich als univeraler Bedeutungshorizont thematisiert, der in die Endgestalt von Husserls Denken mündet. In dieser Endgestalt, erstmals durch die Krisis-Schrift öffentlich dokumentiert, erscheint dieser universale Bedeutungshorizont in der Gestalt des berüchtigten Terminus Lebenswelt. Dieser Terminus ist nicht, wie zunächst gemutmaßt wurde, ein gänzlich neuer Begriff, der quer zu Husserls Phänomenologie als eidetischer Bewußtseinsanalyse stünde, ${ }^{1}$ sondern

1 Diese These ist in der Forschung anfangs mitunter vertreten worden (z.B. von Walter Biemel), wurde aber rasch verworfen. Wie Donn Welton mutmaßt, verwendet Husserl den Begriff „Lebenswelt“ erstmals in seiner Vorlesung von 1919, Natur und Geist, vgl. D. Welton: The Other Husserl. The Horizons of Transcendental Phenomenology. Bloomington 2000. 
faßt nurmehr auf glückliche Weise Husserls Bemühungen um eine umfassende noetisch-noematisch ausgerichtete transzendentale Phänomenologie zusammen. Lebenswelt und transzendentale Subjektivität bilden die beiden Pole einer universalen Korrelation.

Soweit ist alles bekannt; dennoch aber ergeben sich auf den genaueren Blick Probleme und Schwierigkeiten. „Lebenswelt“ ist nämlich nicht einfach nur ein Begriff für „die Welt, in der wir leben“ im Sinne der Umgangs- und teilweise sogar Wissenschaftssprache, sondern ist ein komplexer terminus technicus im Rahmen von Husserls Spätphilosophie unter dem Titel der genetischen Phänomenologie. Genetische Phänomenologie analysiert nicht nur die strukturelle Verfassung intentionaler Akte, sondern deren Entwicklung in einer „intentionalen Geschichte“. In diesem Sinne beansprucht Husserls reife Philosophie, als transzendentale Phänomenologie, ebenso eine Thematisierung der Geschichtlichkeit, d.h. nicht der Geschichte als Faktum, sondern ihrer Interpretation hinsichtlich ihrer transzendentalen Dimension. Erst so könne jedoch die Faktizität der Lebenswelt richtig aufgeklärt werden, d.h. sofern sie als Sedimentationsort intentionaler Akte verstanden wird. Die Faktizität der Lebenswelt ist also nicht ohne die transzendentale Fragestellung zu haben. Das Ganze wird noch dadurch verkompliziert, daß Husserl in seiner Spätphase darum bemüht war, seine Phänomenologie zu einem System auszugestalten. Husserls Phänomenologie unternimmt eine systematische Rekonstruktion der transzendentalen Konstitution der Lebenswelt. Das zumindest ist eine (sehr) rohe Skizze von Husserls Vorstellung einer phänomenologischen Systematik als einer statisch-genetischen Aufklärung der Konstitution von Welt.

Die Endgestalt von Husserls Philosophie stellt sich aber eher als verworrenes Knäuel von Problemen denn als stringent ausgearbeitetes System dar. Das heißt aber wiederum nicht, daß sich nicht doch eine systematische Verzahnung dieser Themen ausmachen ließe. Wie Donn Welton hervorhebt, handelt es sich bei Husserls „systematischer" Spätphilosophie nicht um ein System, sondern vielmehr um eine systematische Methode, die sich in den letzten beiden Lebensjahrzehnten Husserls herausbildet. ${ }^{2}$ Der vorliegende Beitrag unternimmt in diesem

339 (sowie die Endnote hierzu, 460, Nr. 14). Der Passus der Vorlesung, auf den Welton hier verweist, ist nun veröffentlicht in: Edmund Husserl: Natur und Geist. Vorlesungen Sommersemester 1919. Husserliana Materialien, Bd. IV. Dordrecht/Boston/London 2002. 17 f. Anm., interessanterweise in einer gestrichenen (und nicht vorgetragenen?) Passage. Obwohl Husserl das Thema der Lebenswelt bereits weitaus früher behandelt - Welton verweist an dieser Stelle, wie übrigens Husserl selbst mehrmals, auf die Vorlesung 1910/11, Grundprobleme der Phänomenologie, veröffentlicht in Hua XIII -, ist es nicht unwahrscheinlich, dass der Begriff „Lebenswelt" erst 1919 tatsächlich verwendet wird - immerhin doch bemerkenswert früh.

$2 \mathrm{Zu}$ dieser „Systematik“ von Husserls genetischer Phänomenologie, vgl. die Darstellung bei Donn Welton: The Systematicity of Husserl's Transcendental Philosophy: From Static to 
Sinne, ausgehend von dieser These Weltons, das bescheidenere Ziel zu verfolgen, den systematischen Zusammenhang von Lebenswelt, Faktizität und Geschichtlichkeit in Husserls Spätwerk zu rekonstruieren. Diese sind aber nicht beliebig aufgegriffene Termini aus diesem Spätwerk, sondern Kernbegriffe, die einen Einblick in Husserls Phänomenologie der Lebenswelt geben, eine Theorie bzw. Methode, die nicht voll ausgearbeitet vorliegt, sondern noch gewissermaßen „im Rohbau“ steht. Angesichts der Fülle von noch unveröffentlichten Manuskripten zu diesem Thema und des Schlagwortcharakters des Begriffes „Lebenswelt" - der vemuten läßt, es sei zu diesem Thema bereits alles gesagt -, lohnt es, sich Husserls Phänomenologie der Lebenswelt unter den genannten Aspekten erneut anzusehen. Hier gibt es allerdings, wie zu sehen sein wird, noch viele ungelöste Probleme und interessante Aspekte.

Weltons und die vorstehenden Reflexionen stehen damit in einer gewissen Tradition, die u.a. auf Ludwig Landgrebes Arbeiten zurückgeht, welche sich insbesondere auf Husserls Überlegungen zur Geschichte konzentrieren. Einem bekannten Wort Landgrebes zufolge ist die Phänomenologie Husserls in ihrer reifen Gestalt, neben oder zusätzlich zu einer Phänomenologie der Lebenswelt, überdies eine „transzendentale Theorie der Geschichte“. ${ }^{3}$ Die Geschichte ist dies ist selbst ein von Landgrebe oft zitiertes Wort Husserls - das „große Faktum des absoluten Seins“. ${ }^{4}$ Die Faktizität, von der hier die Rede ist, ist - kann man mutmaßen - keine andere als die der Lebenswelt, sofern sich das geschichtliche Menschenleben in der vom Menschen und seinen Leistungen geformten

Genetic Method. In: D. Welton (Hg.): The New Husserl. A Critical Reader. Bloomington 2003. 255-288, sowie seine breitere, aber im Wesentlichen die gleichen Thesen vertretende Ausführung in The Other Husserl (op. cit.), Kap. 13-15. Welton erläutert in beiden Darstellungen seine These, daß es sich bei Husserls „System“ weniger um eine Systematik handelt, wie man sie aus den Systembemühungen des Deutschen Idealismus kennt, sondern daß Husserls „System“ vielmehr als eine systematische Methode zu verstehen sein müsse („The Systematicity of Husserl's Transcendental Philosophy“, 282, „[...] Husserl as developing not a system of philosophy but a philosophical method"). Ich werde hierauf zurückkommen. Seine These ist im Allgemeinen, daß „Husserl's most enduring discovery was how a transcendental characterization of subjectivity and a transcendental characterization of world mediate each other" (The New Husserl, op. cit., 223). Vgl. hierzu auch neuerdings Christian Bermes: ,Welt‘ als Thema der Philosophie. Vom metaphysischen zum natürlichen Weltbegriff. Hamburg 2004 (v.a. Kap. III und IV). Auf Weltons wie Bermes' Arbeiten wird zurückzukommen sein.

3 Vgl. Ludwig Landgrebe: Faktizität und Individuation, Studien zu den Grundfragen der Phänomenologie. Hamburg 1982. IX, sowie: Meditation über Husserls Wort ,Die Geschichte ist das große Faktum des absoluten Seins'. Ebd., 43. Vgl. auch: Phänomenologische Bewußtseinsanalyse und Metaphysik. In: Der Weg der Phänomenologie. Das Problem einer ursprünglichen Erfahrung. Gütersloh 1963. 75 ff., hier v.a. 100 ff.

${ }_{4}$ Vgl. die berühmte Beilage XXXII in: Hua VIII, 497 ff., insbes. 506, vgl. hierzu Landgrebes Texte, die diese Passagen ausführlich kommentieren und inzwischen Klassiker der Husserlforschung geworden sind: Meditation über Husserls Wort ..., sowie: Faktizität und Individuation. Beide wieder abgedruckt in: Faktizität und Individuation. op. cit. 38-57 bzw. 102-116. 
Welt, also der Lebenswelt im prägnanten Sinne, abspielt. Das setzt allerdings einen sehr weit entwickelten, speziellen Begriff von Faktizität voraus, den es eigens zu explizieren gilt. Soll mit „Faktizität“ nicht einfach das gemeint sein, was Heidegger z.B. in seiner „Hermeneutik der Faktizität“ behandelt, so ist dieser Begriff in seiner Verklammerung mit der transzendentalen Fragestellung zu erläutern. Dies ist die eigentliche Herausforderung für den Interpreten von Husserls Spätwerk.

Andererseits, ohne allzu große Allgemeinheiten verkünden zu wollen, kann man sagen, daß die Geschichte, von der Husserls Phänomenologie als deren „transzendentale Theorie“ handeln soll, ebenfalls die der Lebenswelt ist, da alles weltliche Leben wesenhaft geschichtlich verläuft und als solches in der Welt terminiert. In welchem Sinne genau von "Geschichte“ gesprochen wird, ist ebenso noch klärungsbedürftig. Daß es eine Beziehung zwischen Lebenswelt, Faktizität und Geschichte gibt, dürfte also wenig Widerspruch hervorrufen. In der Forschung allerdings ist die Beantwortung der Frage nach ihrem Beziehungsgefüge zumeist von Seiten der Geschichte oder von der Frage, inwieweit die Phänomenologie als Geschichtsphilosophie fungieren kann, aufzurollen versucht worden. ${ }^{5}$ Statt der Frage aber, inwiefern die Lebenswelt ein Element der Geschichtlichkeit oder der transzendentalen Geschichte ist, möchte ich hier die Problematik umzudrehen versuchen und fragen, inwiefern eine phänomenologische Theorie der Lebenswelt umgekehrt der Geschichtlichkeit für eine Aufklärung ihrer Konstitution bedarf.

Was für den Begriff der Geschichte im Rahmen der Phänomenologie gilt, kann man auch für den zweiten im Titel genannten Terminus feststellen. Auch hier hat man sich eher dafür interessiert, was „Faktizität" isoliert und für sich betrachtet beim späten Husserl zu bedeuten hat und was etwa ihre Beziehung zu der Faktizität ist, deren „Hermeneutik“ als Gegenprogramm zu Husserls transzendental-subjektiver Vorgehensweise angesehen werden kann, ${ }^{6}$ - anstatt

5 Vgl. hierzu David Carr: Phenomenology and the Problem of History. Evanston/Ill. 1974. Vgl. insbes. Kap. 5, 110 ff., worin dieser Versuch unternommen wird. So spricht Carr von einer „historischen Reduktion“, die die Geltungsursprünge der Welt als historischer aufklären will. Vgl. auch seine rezenteren Studien in: Interpreting Husserl. Critical and Comparative Studies. Dordrecht/Boston/Lancaster 1987 (Phaenomenologica 106). Insbes. Text Nr. 3, 71 ff., sowie Text Nr. 10, 213 ff., und Nr. 11, 227 ff. Vgl. auch weiterhin Karl-Heinz Lembeck: Gegenstand Geschichte. Geschichtswissenschaftstheorie in Husserls Phänomenologie. Dordrecht/Boston/London 1988 (Phaenomenologica 111). Zum Begriff der Faktizität vgl. insbes. ebd. 231-34.

6 Aus dieser Perspektive wird Husserls Rede von der Phänomenologie als „Hermeneutik des Bewußtseinslebens" (vgl. Hua XXVII, 177) in ihrer vollen kritischen Schärfe deutlich. Während für Martin Heidegger die Phänomenologie als „Hermeneutik der Faktizität“ das alltäglich-durchschnittliche Leben des Menschen auslegen soll, ist ein „hermeneutisches“ Verfahren für Husserl auf das Bewußtseinsleben anzuwenden, welches aber als Korrelat die in seinen 
daß dieses Problem mit einer Reflexion bezüglich des Programms einer Ontologie der Lebenswelt verknüpft worden wäre. „Faktizität“ wird zumeist ausschließlich in der Opposition zu „Wesen“ oder „transzendental“ verstanden, wobei m.E. gerade die Frage nach dieser vermeintlichen „Opposition“ die eigentlich brennende ist. Mit der Frage, wie sich beim späten Husserl „Faktizität“ definiert, ist der Status seiner Phänomenologie als transzendentaler untrennbar verknüpft. Ohne diese Fragen - etwa die Beziehung zu Heidegger - wiederum als sinn- oder gegenstandslos abtun zu wollen, interessiert mich hier die umgekehrte Frage, inwiefern Faktizität, gerade in ihrer Beziehung zur Sphäre des transzendentalen Bewußtseins, Bestandteil einer ausgereiften Theorie der Lebenswelt sein muß. Es genügt also nicht, Faktizität als bloße „Tatsächlichkeit“ und die Lebenswelt damit schlichtweg als „faktische Welt des Lebens“ zu verstehen, sondern es muß geklärt werden, inwiefern Faktizität in ihrer eigentümlichen Bedeutung ein notwendiger Bestandteil der Lebenswelt ist und in ihrem originellen Sinn zusammen mit dem Phänomen der Geschichtlichkeit das Koordinatensystem einer „Ontologie der Lebenswelt“ umreißt oder zumindest vorzeichnet. Schließlich muß der innere Zusammenhang dieser Phänomene expliziert werden, sollen beide Elemente nicht bloß untergeordnete Theorienelemente einer umfassenderen Lebenswelttheorie sein, sondern systematische Funktion darin und für sie haben.

Zunächst soll hier Husserls reifes Programm einer „Ontologie der Lebenswelt" rekonstruiert werden. Es wird zu zeigen sein, daß eine nach allen Seiten ausgeführte Besinnung hinsichtlich der Auslegung der Lebenswelt eo ipso auf das Phänomen der Geschichte stößt. Im zweiten Teil soll dargelegt werden, wie die Charakterisierung der Geschichte im Rahmen der transzendentalen Fragestellung auf eine eigentümliche Bestimmung von Faktizität hinausläuft. Letztlich ist

Leistungen konstituierte Lebenswelt hat. Auch in einer Husserlschen „Hermeneutik“ geht es letztlich um die Lebenswelt, aber als Korrelat zum weltkonstituierenden transzendentalen Bewußtsein. Im gerade zitierten Vortrag Phänomenologie und Anthropologie, der als Replik auf Max Scheler und v.a. Heidegger intendiert war, fährt Husserl etwas weiter unten fort: „Nach all dem verstehen wir auch, daß die Umwendung von der naiven Weltforschung zur Selbsterforschung des transzendentalen egologischen Bewußtseinsbereichs nichts weniger bedeutet als eine Abwendung von der Welt und einen Übergang in eine weltfremde und darum interesselose theoretische Spezialität. Im Gegenteil: Es ist die Wendung, die uns eine wirklich radikale Welterforschung, ja wie sich zeigt darüber hinaus, eine radikal wissenschaftliche Erforschung des absoluten, des im letzten Sinne Seienden ermöglicht.“ (ebd. 178) Zu Husserls Projekt einer „hermeneutischen Phänomenologie“ im Verhältnis zu Heidegger bzw. den Neukantianern, vgl. vom Verf.: Husserl's Concept of the Transcendental Person. Another Look at the Husserl-Heidegger Relationship. In: International Journal of Philosophical Studies 13/2 (2005). 141-177, sowie: A Hermeneutic Phenomenology of Subjective and Objective Spirit: Natorp, Husserl and Cassirer. In: The New Yearbook for Phenomenology and Phenomenological Philosophy IV (2004). 209-249. 
zu zeigen, wie Husserls Verhältnisbestimmung von transzendental und faktisch entscheidend ist für sein Verständnis von der geschichtlichen Lebenswelt und ihres "Sinnes“.

\section{Das Programm einer „Ontologie der Lebenswelt“ und das Problem der Geschichte}

Vor allem zwei grundlegende und innerlich zusammengehörige Entwicklungen in Husserls Spätphilosophie - eine methodische, eine sachliche - führen ab den 20er Jahren zur späten Konzeption der Lebenswelt und deren „Ontologie“:

\section{A) Von statischer zu genetischer Phänomenologie ${ }^{7}$}

Husserls sogenannte "Wende zur Geschichte“ in der Krisis wird in Wahrheit bereits mehr als ein Jahrzehnt zuvor durch die Erweiterung der Phänomenologie als „statischer" in Hinblick auf die genetische Dimension vorbereitet. ${ }^{8}$ Grundle-

7 Die m.E. klarste und umfassendste Darstellung der Entwicklung von Husserls genetischer Phänomenologie gibt Donn Welton in: The Other Husserl, op. cit., v.a. Part I. Wichtig an Weltons Interpretation ist, daß er zeigt, wie Husserls Wende zur genetischen Phänomenologie folgerichtig ist und im Prinzip bereits schon in den Logischen Untersuchungen vorgezeichnet ist. Damit wendet er sich gegen die sog. „Standardinterpretation“, die Husserls Spätphilosophie als bloßen „afterthought“ bzw. als widersprüchlich mit seiner früheren Phänomenologie ansieht. Im Cambridge Companion to Husserl etwa (hg. v. Barry Smith und David Woodruff Smith [Cambridge 1995]) ist nicht ein einziger Beitrag Husserls Spätphilosophie gewidmet (mit Ausnahme des Beitrags ,Transcendental Idealism` von Herman Philipse, der zumindest einen Blick auf das Spätwerk wirft).

${ }^{8}$ Husserls Selbstinterpretation zufolge beginnt die genetische Phänomenologie allerdings sogar bereits in der Göttinger Zeit, vgl. seinen Brief an Paul Natorp vom 29.6.1918 (HuaBriefwechsel, Bd. 5. 137): „wobei ich noch bemerken darf, daß ich schon seit mehr als einem Jahrzehnt die Stufe des statischen Platonismus überwunden u[nd] der Phänomenologie als Hauptthema die Idee der transcendentalen Genesis gestellt habe“. Diese Auskunft ist in erster Linie als statement seinem Briefpartner gegenüber zu verstehen, der seine rekonstruktive Psychologie in der Allgemeinen Psychologie nach kritischer Methode im Jahre 1912 veröffentlichte, also ein Jahr vor der Veröffentlichung der Ideen I. Husserl las dieses Buch ausführlich im Spätsommer 1918 und behandelte es in seinem Seminar von 1922/23. In seinen ausführlichen Randbemerkungen wird deutlich, daß er in Natorps Darstellung bereits eine „genetische" Psychologie am Werk sieht, allerdings mit schiefen Darstellungen behaftet. Was Husserl als Genesis bzw. genetische Methode bezeichnet, läuft bei Natorp unter dem Begriff der „Rekonstruktion“, vgl.: Allgemeine Psychologie. Tübingen 1912. 83: „So ist vor allem das Empfindungsdatum nicht, als Subjektives, voraus ,gegeben', in dem Sinne, daß es vorher bekannt (das hieße ja: fertig bestimmt) wäre; sondern die psychologische Rekonstruktion hat es erst aufzustellen und zu definieren als die voraus, gegebene' Möglichkeit (Potenz) aller der Bestimmungen, welche die objektivierende Erkenntnis an ihm wirklich vollzieht." Natorp stellt seiner 
gende Einsicht ist hier, daß das Bewußtseinsleben - wie bereits die Analyse des Zeitbewußtseins zeigt - einen prozessualen, dynamischen Charakter hat, welcher der statischen (konstitutiven), lediglich an der Oberfläche forschenden Beschreibung von noetisch-noematischen Aktververhältnissen entgeht. Noesis und Noema werden in der ersten Darstellung lediglich als „starre“, „fertig“ konstitutierte Phänomene thematisiert. Dies ist möglich nur dann, wenn man den zeitlichen Charakter des Bewußtseins absichtlich ausblendet, wie dies Husserl in Ideen I von 1913 tat (und dies nachträglich, im Nachwort von 1930, an seiner eigenen Darstellung kritisiert). ${ }^{9}$ Stellt man sich die statische Analyse metaphorisch als zweidimensional vor, thematisiert die genetische die dritte, die Tiefendimension. Alle intentionalen Vorgänge (der „Oberfläche“) weisen auf eine „Tiefenschicht“, in der ein gegenwärtiger Akt „vorbereitet“ wurde, d.h. seine Genesis hatte, sei es in früheren Akten, die in „Passivität“ versunken sind, oder „rein passiven“ Vorgängen, die den im eigentlichen Sinn zu nennenden Akten vorausliegen. Alles aktuelle Verhalten ist fundiert auf früheren Akten, sowie auf passiven „Aktvorgängen“ wie z.B. Motivationen und Assoziationen. Im Zusammenhang der Beschreibung dieser dynamischen Verhältnisse und ihrer Gesetzmäßigkeiten spricht Husserl erstmals - und wohl nicht zufällig mit Blick auf den Deutschen Idealismus - von einer "Geschichte“ des Bewußtseinslebens. ${ }^{10}$ Diese Geschichte des Bewußtseins selbst hat gesetzmäßige Verlaufsformen, und diese können als solche in ihrer Wesenhaftigkeit aufgewiesen und beschrieben werden. Die genetische Phänomenologie ist also nach wie vor eidetisch. Eine so aufgewiesene Geschichtlichkeit als genetische Wesensgesetzlichkeit regelt und formt erst so etwas wie die faktische Entwicklung des konkreten Bewußtseinslebens eines Menschen, z.B. der Entwicklung von Charaktereigenschaften oder eines konkreten Habitus. ${ }^{11}$ So geht jeder Habitualität, jedem Habitus des kon-

Psychologie also die Aufgabe einer „genetischen Rekonstruktion“, tut dies jedoch, wie Husserl kritisiert, ohne zuvor die transzendentale Reduktion durchzuführen; Psychologie ist also die „Minus“- zur „Plusbewegung“ der transzendentalen Methode (der Konstruktion von Realität, entwickelt von Hermann Cohen). Natorps Psychologie ist also in Husserls Einschätzung eine naive, vor-transzendentale Bewußtseinswissenschaft, oder genauer, wie Welton schreibt, "[f]rom Husserl's perspective after the transcendental turn, Natorp's analysis could be viewed only as an unwelcome mixture of psychological and transcendental analysis." (Welton: The Systematicity of Husserl's Transcendental Philosophy. Op. cit. 270) Dennoch darf der Einfluß Natorps auf Husserls genetische Phänomenologie nicht unterschätzt werden, ein Einfluß, von dem sich Husserl durch die zumindest zweifelhafte Datierung seiner genetischen Wende zu distanzieren versucht.

9 Vgl. Hua V, $155 \mathrm{ff}$.

10 Vgl. Hua XI, 339, sowie Hua I, 109, \37.

11 Dieser genetisch gewordene Habitus mit seinen Meinungen, Überzeugungen und Charaktereigenschaften ist vom Ich selbst nicht zu trennen, wie Husserl in einer Beilage zu Ideen II sagt, „die Überzeugung ändern ist, sich“ ändern. Aber in der Änderung und Unveränderung ist das Ich identisch dasselbe eben als Pol.“ (Hua IV, 311) 
kreten Menschen wesensmäßig eine Geschichte von Habitualisierungen voraus, die wiederum „eidetisch“, gesetzmäßig, auf eine Urstiftung zurückgehen und von da an Entwicklungsstadien gemäß einer „,inneren“ Gesetzmäßigkeit durchlaufen. Jede faktische Entwicklung hat also eine wesensmäßige Verlaufsstruktur. Aufgabe einer genetischen Phänomenologie ist die Aufweisung von „Gesetzen der Genesis"12 als Regeln einer faktischen Entwicklung. Dies ist der Zusammenhang, worin bei Husserl erstmals das Phänomen der Geschichte - als Geschichte oder Genesis des Bewußtseinslebens nach wesensmäßiger Form - thematisiert wird. ${ }^{13}$ Der Sinn von Geschichte ist hier jedoch noch nicht scharf herausgearbeitet, sofern sie die geschichtliche Entwicklung (Genesis) innerhalb eines konkreten Bewußtseins, einer „Monade“, meint, gleichzeitig aber auch Wesensgesetze der Genesis, nach der sich die konkrete Monade gesetzmäßig entwickelt (Geschichtlichkeit).

\section{B) Von Ding zu Horizont}

Husserls Untersuchungen der Struktur des intentionalen Bewußtseins führen ihn zu einer Ausweitung des ursprünglichen intentionalen Verhältnisses von Aktvollzug und darin gegebenem Ding, das in der transzendentalphänomenologischen Reduktion zum Phänomen wird. Die Methode von Epoché und Reduktion klammert hierbei den naiven Glauben an das An-sich-Sein der Welt ein und reduziert es auf Erfahren-Sein, korrelativ auf Sich-Gebendes in jeweiligen Erfahrungsmodis (Meinen, Urteilen, Werten etc.). Das Erscheinende im erfahrenden Bewußtsein wird in seiner Gegebenheit für dieses thematisch und in den wesentlichen Weisen seiner Gegebenheit analysiert, im Fall der paradigmatischen Wahrnehmungsanalyse etwa in seiner Gegebenheit in Abschattungen. So weit ist der durch die phänomenologische Reduktion eröffnete Unter-

12 Hua XI, 336.

13 Vgl. hierzu insbesondere Husserls große, in der ersten Hälfte der zwanziger Jahre mehrmals gehaltene Vorlesung über „transzendentale Logik“ (veröffentlicht in Hua XI, XVII und XXXI; vgl. auch die Rekonstruktion der Vorlesung in Hua XXXI, 141 f.). Zur Rekonstruktion von Husserls Wende zur genetischen Phänomenologie vgl. wiederum die detailreiche Studie von Welton: The Other Husserl. Op. cit. v. a. Teil I, 13-256. Ferner ist daran zu erinnern, daß Husserl in der Zeit, als er seine „genetische Logik“ ausarbeitete, sich mit geschichtsphilosophischen Fragen auseinander zu setzen begann. Diese trug er vor etwa im ersten Teil der berühmten Vorlesung von 1923/24, Erste Philosophie, Hua VII/VIII. Diese Zusammenhänge sind ebenfalls bei Welton rekonstruiert, insbes. im Zusammenhang mit Husserls „kulturphilosophischen“ Überlegungen in den Kaizo-Artikeln aus der gleichen Periode, vgl.: The Other Husserl. Op.cit. Kap. 12, 306 ff. Welton zeigt hier sehr plausibel, wie diese Themen - transzendentale Logik, Kulturphilosophie, Geschichtsphilosophie - in Husserls Spätwerk systematisch zusammenhängen. 
suchungsrahmen vorgezeichnet. Das Neue an Husserls Analysen in der Zeit nach den Ideen I liegt aber in folgender entscheidender Einsicht, die mit der phänomenologischen Methode von Epoché und Reduktion zusammenhängt. Die Epoché klammert nämlich universal den gesamten Weltglauben ein, der in der „natürlichen Einstellung“ für selbstverständlich hingenommen wird. Das heißt: Was sich in dieser Einstellung gibt, ist immer schon gegeben in einem Feld oder Kontext von Mitbewußtem, Mitgegebenem, aber nicht aktuell Bewußtem, Gegebenem. Ein intentionaler Akt erweist sich in Wirklichkeit als ein realisierter Aktus aus einer Unendlichkeit von „vermöglichen“ (potentiellen) anderen. Diesen Vermöglichkeiten von Aktvollzügen entspricht aber etwas auf der noematischen Seite. Zunächst verweisen, noetisch gesehen, potentielle Akte auf eine Endlosigkeit von Seiendem, dem man sich zuwenden kann. Auf „subjektiver“ (noetischer) Seite wird diesem Umstand durch den Einstellungsbegriff Rechnung getragen: Eine Einstellung ist eine generelle Haltung, „aus“ welcher potentielle Akte (unendlich viele) mit einer bestimmten „Meinung“ der Vermöglichkeit nach hervorkommen können. Eine spezifische Einstellung ist durch die Interessehaltung charakterisiert, d.h. in der Einstellung als Künstler, als Wissenschaftler etc. Eine Einstellung ist dadurch bestimmt, daß ein Interesse alle potentiellen Gegenstände betreffen kann (also nicht auf eine festgelegte Anzahl von Seiendem bezogen ist) bzw. nur das wahrnimmt, was dem Interesse dient.

Auf „objektiver“ (noematischer) Seite spielt sich Analoges ab: Zunächst kann der wahrgenommene Gegenstand in endlosen Abschattungen erscheinen und sich in diesen Abschattungen unendlich differenziert darstellen. Der Gegenstand

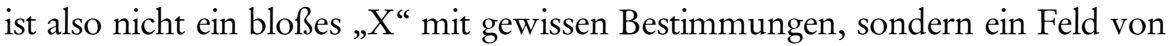
möglichen Erscheinungsfacetten; Husserl nennt dies den „Innenhorizont“. Aber auch der „Außenhorizont“ eines Dinges ist eine endlose Unbestimmtheit, insofern von gegebenem Gegenwärtigen zu ungegebenem, aber geb-barem Gegenwärtigen eine Verweisungsstruktur läuft: Das gesehene Haus zeigt sich von der Vorderseite, wobei die Rückseite ,impliziert“ ist, aber es verweist zugleich auf den zugehörigen, aber gegenwärtig unthematischen, mitgemeinten Garten etc. Die Endlosigkeit bezieht sich nicht auf eine (mehr oder minder umfangreiche) Unzahl von Seiendem, sondern auf eine Offenheit, worin Seiendes zur Gegebenheit kommt. Dieses Feld ist nichts anderes, als was Husserl mit „Horizont“ bezeichnet. Alles Erscheinende gibt sich in einem Horizont, der aktuell un-, aber mitbewußt ist und in den man (im Falle der äußeren Wahrnehmung) in Aktualisierung kinästhetischer Vermöglichkeiten eindringen kann (ich kann um das Haus herumlaufen, die Rückseite betrachten und den dahinter liegenden Garten betreten, Pflanzen betasten etc.). Diesen Horizont als Sphäre des aktuell und potentiell Gegebenen bezeichnet Husserl nun auch als Welt. Die Umwelt des bekannten Gartens, worin die Kinder spielen etc., ist eingebettet in den grö- 
ßeren Horizont der Stadt, diese wiederum in den Landstrich etc. Die wiederkehrende Verwendung von „etc.“ ist hier also kein Zufall. Die Welt als Verweisungsstruktur hat den prinzipiellen Charakter eines „Und-so-weiter.“ Die Lebenswelt als Titel für den „Horizont aller Horizonte“ ist also vor dem Hintergrund dieser Ausweitung der Intentionalitätstheorie zu verstehen. Im gleichen Sinne ist die natürliche Einstellung als Grundcharakter alles menschlichen Verhaltens die „Einstellung aller Einstellungen“, die durch die „Generalthesis“ charakterisiert ist („die Welt existiert"). Auf beiden "Seiten“ der noetischnoematischen Intentionalitätsstruktur zeigt sich also die entscheidende Neuentwicklung die Entdeckung des Horizontphänomens.

Näher diese Struktur betrachtend ist es v.a. ein Begriffspaar - Gegebenheit/ Vorgegebenheit -, das Husserl eingehend analysiert und welches mit der Horizonthaftigkeit der Erfahrung zusammenhängt; in diesem Zusammenhang kommt das Phänomen der Zeitlichkeit der Erfahrung neuerdings ins Spiel.

Wenn das Gegebene in einen Horizont „eingebettet“ ist, aus dem es erscheinen und sich allererst geben kann, so folgt, daß der Horizont eine Priorität "vor“ dem einzelnen Erscheinenden selbst hat. ${ }^{14}$ Die Gegebenheit setzt eine VorGegebenheit voraus. „Gegebenheit“ und „Vorgegebenheit“ sind das Begriffspaar, das der Struktur von erscheinendem Ding und Horizont parallel läuft. Dabei hat offenbar das "vor" in Vorgegebenheit auch und vornehmlich eine zeitliche Bedeutung. ${ }^{15}$ Jede Gegebenheit von Erfahrenem setzt selbst eine Vor-Gegebenheit voraus, die dem Gegebenem logisch wie zeitlich vorangeht und sein Erscheinen vorbereitet oder "ermöglicht“. In der zeitlichen Verwendungsweise des Begriffs besagt „Vorgegebenheit“ frühere Gegebenheit. Jede gegenwärtig gegebene, durchlebte Gegenwart von Erfahrenem, wie auch die Gegenwart des Erfahrens selbst, ist immer nur „aus“ Vergangenheit, die frühere Gegenwart war. Die „lebendige Gegenwart“ ist lebendig deswegen, weil sie eine dynamische zeitliche Struktur hat, in der sie von Gegenwart zu Gegenwart fortschreitend verläuft,

14 Dies wird ebenfalls in vielen Darstellungen, die kritisch mit Husserls „Mythos des Gegebenen" (Wilfried Sellars) ins Gericht gehen, übersehen. Die Vorgegebenheit der Welt ist fundamentale Voraussetzung für jede Gegebenheit. Was Husserl also voraussetzt, ist nicht, daß etwas gegeben ist, sondern, daß jede potentielle Gegebenheit einen vorgegebenen Horizont - der ja nicht selbst erscheint oder wie ein Gegenstand gegeben ist - hat. Zu einer Verteidigung Husserls gegenüber dieser bekannten Kritik von Sellars, vgl. Gail Soffer: Revisiting the Myth: Husserl and Sellars on the Given. In: The Review of Metaphysics 57 (2003). 301-337.

15 Ich sage ,auch“, weil mir die zeitliche Bedeutung oder Dimension nicht die einzige zu sein scheint. Das „vor“ im deutschen Wort „Vorgegebenheit“ hat schlicht die Bedeutung von „vorhanden“ oder „verfügbar“ (z.B. „,ich gebe etwas vor“ = „ich stelle etwas zur Verfügung“). In der Übersetzung in andere Sprachen (z.B. Englisch pregivenness, Französisch prédonation) wird hauptsächlich der zeitliche Sinn betont. Daß die Welt „vorgegeben“ ist, heißt bei Husserl, daß sie schlichtweg vorhanden ist; bei näherer Betrachtung hat dieses Vorhandensein jedoch eine zeitliche Struktur. 
aber schon verlaufen ist mit gewissen Ereignissen - und weiter verlaufen wird in eine noch ungewisse, aber mit mehr oder weniger bestimmter Antizipation präsumierte Zukunft. Die Erfahrungsgegenwart ist der berühmte stehend-strömende „heraklitische Fluß“. Das heißt aber auch, daß die Gegenwart eine bestimmte Struktur hat, die ihr von der Vorgegebenheit früherer erlebter Gegenwarten her vorgezeichnet ist. Gegebenheit ist immer „aus“ Vorgegebenheit, und diese zeichnet - durch Bewährung und Korrektur - die Struktur und Typik der Gegebenheit für die jeweilig erlebte lebendige Gegenwart vor. Die Gegebenheit hat ihre Typik und ihren „Seinsstil“ aus der Vorgegebenheit. Vorgegebenheit verweist also auf Genesis, bzw. ist ein Produkt einer derartigen Entwicklung. Weil die Erfahrung eines Bewußtseins zeitlich verläuft, kann die gegenwärtige Erfahrung nicht anders verlaufen als in einer Typik, die ihr aus früherer Erfahrung her vorgezeichnet ist. Diese Typik ist aber nichts Statisches, sondern etwas, was seinerseits zeitlich geformt wurde und in ständigem Fluß ist. Aus diesem Grund liebt Husserl die heraklitische Metapher vom stehend-strömenden Fluß.

Zusammengefaßt sind die beiden wesentlichen Erweiterungen in Husserls Spätphilosophie, die in die phänomenologische Bestimmung der Lebenswelt eingehen:

1. Bewußtseinsakte in ihrer noetisch-noematischen Verfaßtheit sind nicht bloß statisch zu beschreibende Phänomene, sondern haben eine zeitlichdynamische Struktur. Erfahrung, die immer Erfahrung von Welt ist, unterliegt selbst strukturell einer Genesis. Phänomenologisch aufzuklären ist also die Geschichte der Erfahrung von Welt, sofern es um eine Besinnung in transzendentaler Einstellung geht, die also nicht Welt selbst, sondern Erfahrung von Welt thematisiert. Das ist in nuce der Sinn von Husserls transzendentalem Idealismus. Dabei ist die Aufweisung von Gesetzmäßigkeiten dieser Genesis von vorzüglicher Bedeutung. Diese genetische Betrachtung ist also (a) eidetisch, sofern es um „Gesetze der Genesis“ geht, und (b) transzendental, sofern es sich nicht um Welt oder konkrete Welterfahrung handelt, sondern um die Bedingungen der Möglichkeit von Welterfahrung. Wie der Leib etwa eine Bedingung der Möglichkeit von äußerer Wahrnehmung ist, ist die Vorgegebenheit eine Bedingung der Möglichkeit von gegenwärtiger Gegebenheit.

2. Bewußtseinsakte sind nicht bloß auf einen erfahrenen Gegenstand im Wie seines Erscheinens, bzw. Gegebenseins gerichtet, sondern immer auch inexplizit (einstellungshaft) auf den Horizont, worin er sich gibt. Der Horizont ist das Korrelat zu einer Einstellung. Dieser Horizont, in und aus dem sich Gegebenheit aktuell ereignet, ist „immer schon“ vorgegeben, wie Akte „immer schon“ interessengeleitet, d.h. einstellungshaft, sind. Seiendes gibt sich „aus“ der Vorgegebenheit der Welt bzw. setzt diese logisch voraus. Vorgegebenheit ist aber auch zeitlich aufzufassen, sofern Gegebenheit auf vergangenen und sedimentierten 
Gegebenheiten aufruht, die die jeweilige Gegenwart genetisch zu dem gemacht haben, was sie gegenwärtig ist. Der Horizont ist somit nichts anderes als das weitestmöglich ausgedehnte Verständnis der Intentionalität in noematischer Hinsicht.

Beide Elemente komplementieren sich nun in folgender Hinsicht: Erfahrung von Welt ist geschichtlich, insofern sie eine Erfahrungsgeschichte hinter sich „im Rücken" hat, die die Typik und den Stil ihres Lebens durch Bewährungen hindurch geprägt hat und im Weiteren mit einer gewissen Typik vorzeichnet (die freilich ständig im Fluß ist), und Erfahrung ist horizonthaft, insofern sie in einem Horizont eingebettet ist, der eine Gegebenheitsstruktur vorgibt. Dieser Horizont ist selbst in seiner Gegebenheit einer Genesis, also einer geschichtlichen Prozessualität unterworfen, die ihrerseits ihre „Gesetze der Genesis“ hat. In beiden Fällen hat man es mit Strukturen der Erfahrung zu tun, und in beiden Fällen wird man auf eine zeitliche, bzw. geschichtliche Dimension verwiesen: die Geschichtlichkeit der Erfahrung von der Gegebenheit von Welt und die Geschichtlichkeit der Gegebenheit oder der weltlichen Horizontentwicklung selbst; beides sind Seiten einer Medaille. Insofern es sich prinzipiell um Erfahrungsstrukturen als Möglichkeitsbedingungen handelt, worin sich die Welt für ein erfahrendes Bewußtsein nach idealen Gesetzmäßigkeiten aufbaut - in Husserls Worten: „konstituiert“ -, hat man es bei solchen Reflexionen mit transzendental-philosophischen zu tun. Die aufgewiesenen Strukturen sind damit die Bedingungen der Möglichkeit einer konkreten (faktischen) Erfahrung, z.B. eines Menschen auf dem Planeten Erde.

Für eine phänomenologische Theorie der Lebenswelt (als Titel für den Universalhorizont von Erfahrung) bedeutet dies: Diese Theorie muß rekonstruktiv die Welt beschreiben, wie sie sich für ein erfahrendes Bewußtsein gibt, d.h. in ihrer umweltlichen Vorgegebenheit und in der genetischen Struktur, in der die Erfahrung von Welt sich für das erfahrende Bewußtsein aufgebaut und entwikkelt hat - und in weiterer Absicht antizipierend, wie sie sich entwickeln kann oder wird (präsumtiv). In beiden Fällen wird man auf eine "geschichtliche“ Dimension verwiesen bzw. geradezu darauf gestoßen; einmal auf die Geschichte der Erfahrung selbst, das andere Mal auf die Geschichte der Welt, wie sie sich in der Vorgegebenheit geformt und entwickelt hat zu der in der aktuellen lebendigen Gegenwart vorgegebenen, und d.h. aktuell gegebenen und durchlebten. Welt fungiert aber ständig als sinnhafter Horizont für erfahrendes Bewußtsein und ist unabhängig davon undenkbar bzw. für die Phänomenologie ein Anathema. Wie deutlich zu sehen ist, handelt es sich nicht um zwei isolierte Betrachtungsweisen, sondern um die noetischen und noematischen Relata einer Korrelation. Von daher wird verständlich, wie eine derart konzipierte Theorie oder „Ontologie“ der Erfahrungswelt Bestandteil der transzendentalen Phäno- 
menologie, bzw. wie transzendentale Phänomenologie eine Ontologie der Lebenswelt im beschriebenen Sinn sein oder enthalten muß. Es gibt also eigentlich nur eine Ontologie, deren „Methode“ die Phänomenologie ist. Oder wie es Husserl in einem Manuskript von 1934 formuliert: „Ontologie im vollen und ganzen Sinn ist die Ontologie aller apodiktischen (oder ,apriorischen') Wahrheiten von der Welt als einer überhaupt erdenklichen Welt." ${ }^{16}$ Ontologie, methodisch verstanden als Phänomenologie der Welt als Lebenswelt, ist also keine von der transzendentalen Phänomenologie - als transzendentaler Bewußtseinswissenschaft - getrennte Disziplin. Jegliche Trennung von „Ontologie“ (Wissenschaft von der Lebenswelt) und „Epistemologie“ (Bewußtseinswissenschaft) wäre künstlich. Transzendentale Phänomenologie ist vielmehr Theorie der Welt als Lebenswelt, d.h. als Welt der Erfahrung, und Ontologie hat allein als „transzendentale" Disziplin, d.h. als Wissenschaft von der gegebenen Welt, deren Korrelat die transzendentale Subjektivität ist, Sinn. ${ }^{17}$ Wie diese Korrelation nun genau zu verstehen ist, ist Thema des nächsten Abschnitts.

16 Hua XXXIV, 469, vom Frühling 1934. Dieser Text (Text Nr. 34, 467 ff.) steht im Zusammenhang mit Husserls Bestimmung der „Apodiktizität des Ich-bin“, die „nichts weiter als die Apodiktizität des ego cogito in der Epoché hinsichtlich des Seins der im Bewußtsein geltenden Welt" ist (ebd. 469). Das weist erneut darauf hin, daß eine solche Ontologie der Lebenswelt für Husserl untrennbar mit der Reflexion auf das transzendentale, weltkonstituierende $\mathrm{Be}-$ wußtsein, welches aber letztlich nur in der „Undeklinierbarkeit“ der je eigenen Selbstevidenz zugänglich ist, verbunden ist. Vgl. hierzu auch Landgrebe: Meditation über Husserls Wort ... Op. cit. 41-44. Zum Zusammenhang von Lebenswelt, transzendentaler Phänomenologie und Intersubjektivität, vgl. auch Dan Zahavi: Husserl's Transformation of Transcendental Philosophy. In: Welton (Hg.): The New Husserl. Op. cit. 223-51. Zahavis These hier ist (u.a.), daß "the transcendental analysis of the historical past, of the previous generations, and more generally the transcendental phenomenological treatment of meaning, which transcends the finiteness of the subject, must always take its point of departure from the first-person perspective" (246, Kursivierung ergänzt).

17 Vgl. Hua XXXIV, Text Nr. 17, 264 ff. In diesem wichtigen Text, der von der Heideggerschen Frage nach dem „Sein des Seienden“ ausgeht, will Husserl zeigen, daß diese ontologische Fragestellung in Konsequenz zur transzendentalen Fragestellung führt und letztlich die transzendentale Reduktion erfordert. Wie Welton in anderen Worten sagt, wird bei Heidegger also nur die Welt in einem „ontischen“ Sinn thematisch, d.h. als vorgegebene Welt unseres Besorgens, und nicht, wie bei Husserl, zudem in einem „epistemischen“ Sinn, d.h. als Sinngebilde einer leistenden Subjektivität; vgl. Welton: The Other Husserl. Op. cit. 347-370, v.a. 369. Heideggers Weltauslegung im Rahmen einer „Hermeneutik der Faktizität“ ist also für Husserl ganz in guter Ordnung, nur verfehlt und einseitig, wenn Heidegger meint, ohne die transzendentale Fragestellung auskommen zu können. 


\section{Geschichte versus Geschichtlichkeit. Transzendentales Ego und tran- szendentale Menschbeit. Der transzendentale Horizont der Lebenswelt}

Soweit dürfte alles mehr oder weniger inhaltlich bekannt sein, auch wenn der systematische Zusammenhang dieser Strukturen bei Husserl nicht immer zureichend klar wird. Es gibt nun aber noch eine andere „Achse“ in Husserls Spätphilosophie, die zum bisher Ausgeführten gewissermaßen quer steht. Auf ihr kommt man zum Problem der Faktizität, und man nähert sich ihr durch folgende Frage: Wenn das Bewußtsein seine eigene Geschichte hat, die durch die genetische Rückfrage enthüllt werden kann, was ist dann das Verhältnis dieser Geschichte zu dem, was man üblicherweise als "Geschichte“ bezeichnet, bzw. was rechtfertigt es, den gewöhnlichen Sinn von Geschichte einfach auf das Bewußtsein zu übertragen ${ }^{18}$ Offensichtlich ist von Geschichte in einem äquivoken Sinn die Rede, genau besehen in einer zweifachen Äquivokation. Die erste Schwierigkeit besteht in der Unklarheit darüber, wessen Geschichte gemeint ist. In der Weise, wie Husserl das Phänomen der Geschichte im Rahmen der genetischen Methode einführt, wird deutlich, daß es sich in erster Linie um die Geschichte eines Bewußtseinssubjekts, einer Monade, handelt. Zunächst ist die Geschichte eines einzelnen Bewußtseinssubjekts thematisch und nicht die einer Gruppe von Subjekten. „Geschichte des Bewußtseins“ meint also zunächst die Geschichte der Intentionalität eines Einzelsubjekts als Geschichte von dessen Habitus und nicht die Geschichte im „großen“ Sinn, als die Geschichte einer

\footnotetext{
18 Husserl befindet sich hier auch gewissermaßen „in guter Gesellschaft“, sofern die Problematik einer Geschichte des Selbstbewußtseins bereits seit der Frühzeit des Deutschen Idealismus, bei Reinhold, Fichte und va. in Schellings System des transzendentalen Idealismus, und später natürlich bei Hegel, thematisiert wurde. Vgl. hierzu Ulrich Claesges: Geschichte des Selbstbewußtseins. Der Ursprung des spekulativen Problems in Fichtes Wissenschaftslehre 1794-95. Den Haag 1974. Husserl wollte sich nach eigener Aussage spätestens ab seiner Freiburger Zeit (1916) mit dem Deutschen Idealismus intensiver beschäftigen (vgl. den in Anm. 8 zitierten Brief an Natorp in vollem Wortlaut). Eine ernsthafte Auseinandersetzung fand aber wohl nie statt, sondern Husserls Wissen stammte aus zweiter Hand (zu nennen wäre etwa das Interesse seines Schülers Eugen Fink am Deutschen Idealismus). Zu dem wenigen, was Husserl vom idealistischen Gedankengut rezipierte, gehörte wohl mit großer Wahrscheinlichkeit die Konzeption, oder zumindest die Idee, einer transzendentalen Geschichte des Bewußtseins. Vgl. hierzu seine philosophiegeschichtlichen Exzerpte zu Fichte, Jacobi und Schelling, wo das Thema gestreift wird, in B IV 9/12. Inwiefern diese Konzeption der Idealisten, trotz aller Unterschiede bereits im Ansatz, mit Husserls Idee einer genetischen Phänomenologie vergleichbar ist, muß hier jedoch offen bleiben. Einen ersten, breiter angelegten Versuch, einen Denker des Deutschen Idealismus mit Husserl zu vergleichen, macht neuerdings Tanja Stähler: Die Unruhe des Anfangs. Hegel und Husserl über den Weg in die Phänomenologie. Dordrecht/ Boston/London 2003 (Phaenomenologica 170). Zu Husserls Rezeption von Fichte vgl. D. Welton: The Systematicity of Husserl's Transcendental Philosophy. Op. cit. 270-274. Schelling, als den dritten großen Idealisten, hat Husserl nicht rezipiert.
} 
Menschengruppe, eines Volkes oder gar einer Epoche. Beides darf freilich nicht einfach zusammengenommen werden, sondern bildet Stufen der Subjektivität, von der Einzelsubjektivität aufsteigend zur Pluralität von Subjekten, auch wenn das Einzelsubjekt bei Husserl immer methodische Priorität genießt. In beiden Fällen handelt es sich aber um die Geschichte als faktischen Verlauf, um die res gestae.

Zweitens unterscheidet Husserl zunächst nicht zwischen Geschichte als res gestae und als Geschichtlichkeit. Lassen wir die Unterscheidung zwischen Einzelund Gemeinschaftsgeschichte zunächst beiseite. Geschichte kann, wie bereits eben geschehen, entweder den faktischen Verlauf von Ereignissen benennen das faktisch Geschehene und Chronologisierbare, Datierbare -, oder das, was Husserl auch als „innere Geschichte“ im Sinne der Genesis bezeichnet. Was ist das Verhältnis der beiden zueinander und läßt sich beiden methodisch Rechnung tragen? Was hier anklingt, ist nichts anderes als die klassische phänomenologische Unterscheidung von Außen- und Innenbetrachtung. ${ }^{19}$ Diese Unterscheidung ist nicht identisch mit der von Geschichte (der res gestae) und dem, was man üblicherweise als Geschichtlichkeit bezeichnen könnte; Geschichtlichkeit als Wesenszug eines Menschenlebens etwa, das seine kausal zu rekonstruierenden Ereignisse durchlaufen hat. Im Rahmen einer genetischen Aufklärung von Bewußtseinsverläufen handelt die spezifisch phänomenologische Innenbetrachtung von einer Sinnesaufklärung, die gerade nicht kausal zu rekonstruieren ist. Beziehungsweise ist von Kausalität in einem anderen Sinn die Rede, da es sich nicht um Naturereignisse handelt, sondern um solche der geistigen Welt mit ihren eigenen Gesetzen. Man darf nach Husserl also keinem naturalistischen Reduktionismus verfallen. Nicht die Ereignisse selbst in ihrer kausalen Nacheinanderfolge - die sie in der "Außenbetrachtung" natürlich haben müssen - sind für den Phänomenologen von Interesse, sondern die Aufklärung der motivationalen Sinnesstrukturen, welche faktische Ereignisse „ermöglicht“, d.h. motiviert haben. Gegenüber „äußerer" Geschichte (res gestae) gibt es also eine „innere“ Geschichte. Hiervon ist aber wiederum zu unterscheiden eine „innere Geschichte zweiter Stufe", die diese innere Geschichte wiederum der transzendentalen Reduktion unterwirft, also einer, methodisch gesehen, Rekonstruktion der gei-

19 Bekanntlich wird diese Unterscheidung von Husserl im Rahmen von Konstitutionsanalysen in Ideen II (Hua IV) eingeführt und meint dort die naturalistische und die personalistische Betrachtungsweise. Entgegen dieser Bedeutung verwende ich das Begriffspaar von „Innen“ und „Außen“ in Bezug auf die transzendentale und natürliche Einstellung im Sinne des späten Husserl, also im Sinne der Rede von „first-person“ and „third-person perspective“ im angelsächsischen Sprachraum (eingeführt v.a. durch Thomas Nagel). Für einen Vergleich in dieser Hinsicht zwischen Husserl und Nagel, vgl. vom Verf.: ,Idealismo Realista': Una Respuesta Heterodoxa a la Pregunta del Idealismo Trascendental. In: Escritos de Filosofía $N^{\circ} 43$ (2003). Academia Nacional de Ciencias, Buenos Aires. 75-98. 
stigen Motive, die nicht naturalistisch-reduktionistisch verstanden werden dürfen. Es geht also nicht um die „innere Geschichte“ z.B. des amerikanischen Volkes, das etwa den spezifischen „Nationalcharakter“ der Amerikaner formte ohnehin eine problematische Betrachtungsweise -, sondern um die Geschichtlichkeit leiblicher Subjekte-an-sich. Diese Betrachtungsweise ist nur möglich, wenn das Bewußtsein nicht naturalistisch als Teil der objektiven Welt betrachtet wird, sondern als etwas, das Welt in seinen konstitutiven Akten "formt“ und damit wesensmäßig nicht welthaft ist. Das bedeutet, diese Betrachtungsweise wird erst möglich durch die vollzogene transzendentale Reduktion.

Gegenüber „Geschichte“ spricht Husserl daher auch alternierend von Geschichtlichkeit oder Historizität als das, was die genetische Rekonstruktion nach der transzendentalen Wende enthüllt. Sofern die Motivationsstrukturen der inneren Geschichte des transzendentalen Bewußtseins erst die äußere Geschichte formen - gewissermaßen ihre Möglichkeitsbedingungen sind -, bezeichnet Husserl die Geschichte, die in der nach der transzendentalen Reduktion eröffneten Innenbetrachtung zugänglich wird, als transzendentale Geschichte. Nach der Geschichtlichkeit „erster Stufe“ (Rekonstruktion des „Wesens“ einer konkreten Person oder konkreten Menschengruppe) handelt es sich also nun bei „transzendentaler Geschichtlichkeit“ um eine „Geschichtlichkeit zweiter Stufe“. Husserls Phänomenologie interessiert sich also nicht für die individuelle Geschichte einer Person (wie etwa in der Psychoanalyse oder Historie - „wie wurde Hitler zum Diktator?") oder einer Bevölkerungsgruppe (wie etwa in einer soziologisch-historischen Betrachtung - ,wie konnte sich das deutsche Volk zum Nationalsozialismus wenden?"), sondern für die Gesetze der Genesis eines Bewußtseins, sofern es, sei es als Einzel- oder als Gruppenbewußtsein, in eine Welt hineinlebt und diese durch seine passiven und aktiven Intentionalitäten formt („konstituiert“). Diese Unterscheidung von Geschichte und Geschichtlichkeit läuft quer zur Unterscheidung von Faktum und Wesen, sofern jeder Verlauf, der faktische wie der transzendentale, eine eigens zu beschreibende wesentliche Genesis hat. Geschichte verhält sich zu Geschichtlichkeit wie Deskription (vergangener Ereignisse) zu Interpretation (ihres Sinnes). Interpretation ist aber in der transzendentalen Phänomenologie nicht kausale Rekonstruktion des Sinnes von Geschichte, sondern - um das Abstraktionsniveau noch weiter zu „verschärfen“ - Klärung der Genesis von Sinn selbst.

Diese Unterscheidung ist zugegebenermaßen schwer verständlich. Es spitzt sich folglich alles auf die Frage nach dem Verhältnis von Innen und Außen zu, oder, um Husserls Begriffe zu verwenden, auf das Verhältnis von „transzendental“ und „faktisch“. Erst im Kontrast zur faktischen Geschichte kann das, was Husserl mit transzendentaler Geschichte im Sinn hat, deutlich hervortreten. Hierzu gibt es von Husserl klare Aussagen, die auf die zuvor zurückgestellte 
Frage zurückweisen, wessen Geschichte eigentlich gemeint sei. Ansatzpunkt aller transzendentalen Reflexionen - und um eine solche handelt es sich stets im Rahmen von Husserls Theorie - ist stets das Ich, das zunächst, als je eigenes Ego eines Reflektierenden, in seiner primordialen Stufe thematisch wird. Das einzelne Ich, als faktisch Reflektierender („Phänomenologisierender“), findet in transzendental-phänomenologischer Reduktion das transzendentale Ego, zunächst sein eigenes, vor. Diesen solipsistischen Besinnungs-Einsatzpunkt gibt Husserl nie preis. Zunächst muß folglich das Verhältnis von transzendentalem und faktischem Ego dargelegt werden; was bezüglich ihres Verhältnisses gesagt wird, muß sich für Husserl a fortiori auf das von Transzendentalem und Faktischem überhaupt übertragen lassen. Wie verhalten sich also faktisches (konkretes) und transzendentales Ich zueinander?

Gegenüber einem nahe liegenden und daher oft wiederholten Mißverständnis muß betont werden, daß mit transzendentalem und faktischem Ego nicht zwei Ich oder eine dualistische Konzeption des Subjekts gemeint sind. Für Husserl handelt es sich vielmehr um zwei methodisch zu unterscheidende Momente einer Struktur, die lediglich durch ihre jeweilige Perspektive (Einstellung) verschieden sind bzw. nur durch die jeweilige Perspektive überhaupt erst unterscheidbar werden. Es ist jeweils das Ich, wie es in der natürlichen Einstellung als transzendental-konstituierendes durchlebt wird (unthematisch), und wie es in der reflektiven („phänomenologisierenden“) Einstellung thematisch wird. Das faktische Ego ist sich also selbst überhaupt nicht thematisch; das ist gerade seine „Auszeichnung“ in der „natürlichen“ Einstellung. Die natürliche Einstellung ist dadurch charakterisiert, daß sie eben nicht als Einstellung thematisch wird. Wie Husserl in einer interessanten Randbemerkung zu einem Manuskript sagt: „Die Welt als Universum ist in der ,natürlichen Einstellung' im Allgemeinen kein Thema, sonach ist es eigentlich keine Einstellung. Die Welt ist vorgegeben, ist das Feld aller natürlichen Einstellungen im eigentlich thematischen Sinn. ${ }^{" 20}$ Der Unterschied zwischen dem transzendentalen und faktischen Ego ist also der zwischen dem Ego, das erstmals thematisch wird, und dem, das „weltverloren“, intentional „verschossen“ in die Welt hineinlebt, unwissend um seine weltkonstituierenden Leistungen. In der phänomenologischen Betrachtung wird das Ego demnach nicht irgendwie thematisch, sondern als intentionales Feld, das die Welt als Erfahrungswelt durch seine eigene Erfahrung für sich zustandebringt.

Grundsätzlich aber gilt: Das Ich ist ebenso immer transzendental, wie es sich immer schon als psychophysisch apperzipiert in der Welt, d.i. faktisch findet. Das transzendentale Ego hat sich immer schon, in Husserls Worten, „verwelt-

${ }^{20}$ Hua XXXIV, 14, Anm. 
licht“. ${ }^{21}$ Als weltliches Ego kann es nach der transzendentalen Reduktion (der transzendentalen „Rückfrage“) sein transzendentales „Sein“ enthüllen, aber die Enthüllung durch phänomenologische Reduktion kommt der verweltlichten Auffassung seiner selbst als menschlicher Person und seinem Sein als transzendentalem immer zeitlich nach. Das transzendentale Ego ist zwar das próteron tê phýsei, aber nicht pròs hemâs, genau genommen pròs moú. Das weltliche Ich hat kein transzendentales Ego hinter sich - gleichsam im Rücken, dem es sein weltliches Sein „verdankte“ -, sondern das transzendentale Ich „umgreift“ das natürlich-faktische. Das natürliche Ich ist ein „Modus“ des transzendentalen. ${ }^{22}$ Das bedeutet, daß alle faktischen Bestände des Ego zwar transzendental interpretiert werden müssen - d.h. hinsichtlich ihrer konstitutiven Funktionen -, damit jedoch in ihrer Faktizität gerade nicht „aufgehoben“ werden können. Die phänomenologische Betrachtungsweise enthüllt damit lediglich eine Sinnstruktur, die ohne einen Bruch mit der natürlichen Einstellung nicht in den Blick kommen kann; in den Blick kommt hierdurch die korrelative Struktur des intentional verfaßten Bewußtseinslebens, jedoch nicht einfach nur in seiner Faktizität, sondern diese ist nur insoweit interessant, als dies Anlaß zu einer eidetischen Analyse bietet: „Mensch bzw. Welt bezeichnet eine gewisse transzendentale Struktur der transzendentalen Subjektivität. Wenn ich, Wesensmöglichkeiten erwägend, vom Faktum Welt (die für mich den faktischen Sinn hat ,meine und unsere Welt') zu einer möglichen Welt überhaupt übergehe, so habe ich mein faktisches menschliches Sein abgewandelt und <das > der mit mir und für mich seienden Menschen; so habe ich damit implicite aber auch meine faktische transzendentale Monade, mein faktisches transzendentales Menschentum, und das meiner Mitmonaden abgewandelt. Dabei ist es indessen so, daß wir alle, wir MenschenMonaden, also miteinander weltkonstituierend sind, und in einer Welt, die uns Monaden als miteinander seiende Menschen objektiviert enthalten muß.“23

Diese transzendentale Betrachtung enthüllt also, daß die Selbstverweltlichung des weltkonstituierenden, transzendentalen Ego als faktisches, d.h. seiner selbst

21 Zur Husserlschen Theorie der Verweltlichung vgl. vom Verf.: „Phänomenologie der Phänomenologie“. Systematik und Methodologie der Phänomenologie in der Auseinandersetzung zwischen Husserl und Fink. Dordrecht/Boston/London 2002 (Phaenomenologica 166). Kap. 4, insbes. 264 ff., sowie neuerdings James Dodd: Crisis and Reflection. An Essay on Husserl's Crisis of the European Sciences. Dordrecht/Boston/London 2004 (Phaenomenologica 174).

${ }^{22}$ Vgl. Hua XXXIV, Text Nr. 8, 148 ff. Hier handelt Husserl von der Monade jeweils im „Modus der natürlichen Einstellung“ bzw. in dem der transzendentalen Einstellung. Es geht schließlich dem Phänomenologen darum, „die natürliche Einstellung als einen Modus der transzendentalen Einstellung zu erkennen“" (ebd. 154 f.). Zur näheren Interpretation dieser Passage s.o.

${ }^{23}$ Hua XXXIV, 155, von Anfang August 1930, Kursivierung ergänzt. 
als konstituierendes unberwußtes, selbst ein Wesensgesetz des Ego ist. Oder was das gleiche sagt: Sich selbst in seinen transzendentalen Leistungen zu „verhüllen“, ist also selbst ein Wesensgesetz des Ego!

Obwohl Husserl in diesem Zitat bereits über die primordiale Stufe hinausgeht, sei noch kurz bei ihr verweilt. Hier ist es eine, und nicht nur für die Art der menschlichen Faktizität wesentliche Tatsache, die nie aufzuheben ist und durch keine Reflexion modifiziert werden kann, daß das Ego leiblich verfaßt ist und darüber auch eidetisch varrierend nicht hinaus kann. Einen Leib zu haben, ist Bedingung der Möglichkeit, faktisches Ego zu sein (sei es menschlich oder eines andersartigen Lebewesens) und ist gleichzeitig Wesensbestandteil eines faktischen Ego, unabhängig von seiner „Intelligenz“. Wie Husserl einmal sagt: „Der Leib setzt sich selbst voraus“, ${ }^{24}$ d.h. er ist als unhintergehbares Moment des menschlichen Seins einerseits das, was das jeweilige faktische Ego, hier: den jeweiligen Menschen, radikal individuiert, aber andererseits auch dasjenige, was auch ohne eine eigene Reflexion sich dem Ich gewissermaßen „aufdrängt“ und als solches „voraussetzungs“-los ist; ein leibloses (ebenso wie weltloses) Bewußtsein wäre für Husserl ein Widersinn. Was bedeutet das nun für die Verweltlichung des transzendentalen Ego in genetischer Perspektive?

Auf Grund des fortwährend vor sich gehenden Vorgangs der Verweltlichung als natürlich-menschlicher Selbstapperzeption im Laufe der ständig sich vollziehenden Welterfahrung des Menschen ist die faktische Geschichte des psychophysischen Menschen selbst per definitionem die verweltlichte Form seiner transzendentalen Geschichte. Was kann das heißen? Dies zu verstehen ist äußerst schwierig und die Interpretation darf den Unterschied von transzendental und faktisch nicht aufheben oder gar nivellieren. ${ }^{25}$ Die faktisch durchlebte Geschichte des Menschen „realisiert“ die transzendentale Geschichte der transzendentalen Subjektivität; denn sein Leben (Leben überhaupt) kann nicht anders als faktisch verlaufen. „Faktisch zu verlaufen“ heißt nun, daß es ohne Beroußtsein

24 A VII 12/64a, von Februar 1932.

${ }_{25}$ Daß Husserl selbst Probleme hat, sich diesen Unterschied selbst klar zu machen und konsequent durchzuhalten, wird aus folgender Randbemerkung zu einem Manuskript deutlich: „Genesis vor allem kann hier [in der konstitutiven Auslegung] nicht einen weltlichen Sinn einer weltlichen Kausalität haben, sondern einen transzendentalen. Es ist dann aber die Frage, wie diese transzendentale Genesis sich in der menschlichen und tierischen Genesis und in der psychologischen und gesellschaftlichen (pädagogischen) Genesis ,spiegelt'." (Hua XV, 491, aus einem Manuskript von 1932) Die Metapher der „Spiegelung“ des Weltlichen im Transzendentalen stammt ebenfalls aus Natorps rekonstruktiver Psychologie, wo sie einen guten Sinn ergibt, sofern bei ihm transzendentale Philosophie und Psychologie einander entgegengesetzte Betrachtungsweisen sind (die Plus- und Minusrichtungen auf einer Achse). Die Rede von „Spiegelung“ im Rahmen von Husserls Phänomenologie scheint mir dagegen eher fehl am Platz, sofern ja die transzendentale Sphäre einen ganz anderen Charakter als das mundane Ich haben soll. 
seiner eigenen Leistungen verläuft. Es hat zwar, wie Husserl auch sagt, einen "transzendentalen Index“, aber dem natürlichen Bewußtsein fehlt gewissermaßen das „know-how ", wie man diesen Index thematisch macht. „Faktisch“ hieße damit also nicht nur „konkret“ (im Gegensatz zu abstrakt oder eidetisch), sondern gleichzeitig „naiv“ im Sinne der Naivität der natürlichen Einstellung. Durch transzendentale Rückfrage, die die phänomenologische Innenbetrachtung ermöglicht, wird allerdings die transzendentale Sinnkonstitution des Menschen enthüllt, seine „innere Geschichte“, seine „innere Logik“ gewissermaßen, nach der sich die faktische Geschichte ereignet und abspielt (bzw. gesetzmäßig abspielen muß). Es ist dies aber die Geschichte zunächst eines Ego, das leiblich fungierend diese Form von Faktizität nicht verlassen kann. Das Fungieren des Leibes ist selbst etwas, was nicht nur im natürlichen Bewußtsein nicht thematisiert wird, sondern was in der Philosophie selbst bisher unbeachtet war; Husserl hebt daher zu recht hervor, daß die Unterscheidung von Körper und Leib (letzteres als fungierende Subjektivität) eine der originellsten Entdeckungen der konstitutiven Phänomenologie ist. ${ }^{26}$ Die Leiblichkeit lebt sich aber notwendig aus in einer faktischen (d.h. konstituierten) Welt, die in erster Linie vom Leib geformt wird (etwa durch Tun und Bearbeiten). So gehören Ich als faktisches (qua Leib) und Welt untrennbar zusammen, insofern die Welt der Schauplatz ist, auf dem sich das leibliche Fungieren abspielt. Alles Verhalten zur Welt ist leiblich und nicht etwa leiblich „vermittelt“; denn es gibt hier keine mittlere Instanz zwischen transzendentalem Ego und Welt. Ego und Welt sind, wie Merleau-Ponty sagen würde, „aus einem Fleisch“.

Landgrebe hat diese Zusammenhänge bereits früh erkannt, als er die Identifikation von Faktizität und Transzendentalität des Ego beim späten Husserl im Sinne des leiblichen Fungierens des faktischen Subjekts interpretierte. ${ }^{27}$ Diese kurze Andeutung kann nach dem Gesagten dahingehend weitergeführt und ergänzt werden, daß das natürliche Ego als leiblich verfaßtes nichts von seiner Transzendentalität Getrenntes, sondern daß das natürlich-faktische Ich ein „Modus“ - nämlich der unenthüllte, um seinen transzendentalen Ursprung unwissende des vollaufgeklärten Ego als transzendentalen ist. Die „natürliche Einstellung“ und nicht etwa das natürliche Ego selbst - ist ein „Modus der transzendentalen

26 Vgl. Hua IV, 143 ff. sowie Hua IX, 108. Dies hebt u.a. auch Klaus Held in seiner souveränen Darstellung: Husserl's Phenomenology of the Life-World. In: The New Husserl. Op. cit. 50, hervor. Wie auch Bermes (op. cit. 205) treffend sagt: „Mittels der Auslegung von, Welteinstellungen' des leiblich verankerten, interpersonal handelnden und historisch sich zeitigenden Subjekts reformuliert die Phänomenologie [Husserls] das Weltproblem oder den Weltbegriff als ein Thema, das den unterschiedlichen Ansprüchen nach beschrieben werden kann."

27 Vgl. Meditation über Husserls Wort ... Op. cit. 45-47. 
Subjektivität“". ${ }^{28}$ Es ist aber ein Wesensgesetz eines faktischen Ego, in einer Einstellung behaftet zu sein, genauso wie es wesenhaft immer in einer Welt leibhaft lebt. Das Thema „Leib” soll im Folgenden nicht weiter bemüht werden - es gibt nicht so etwas wie einen ,intersubjektiven Leib“ -, sondern dient im vorstehenden Zusammenhang nur einer weiteren Charakterisierung dessen, was „Faktizitität" bezüglich des Ego bedeutet. Das leibliche Fungieren des Ego ist nurmehr ein zusätzlicher „Garant“ dafür, daß das Ego durch und durch „welthaft“ ist, zur Welt gehört, weil es wesenhaft von gleicher „Materie“ wie sie ist. Der Leib ist der unverlierbare „Anker“, der das Ich mit Welt verkoppelt. Ferner gehört wesenhaft dazu, in einer Einstellung zu sein, von diesem In-Einstellung-Sein zunächst nichts zu wissen. Die Naivität der natürlichen Einstellung ist also kein zufälliger Zustand, der einfach überwunden werden könnte, sondern ein Wesensbefund eines faktischen Ego. Daher kann nur ein radikaler Bruch mit der natürlichen Einstellung aus dieser „Selbstverhüllung“ befreien.

Man darf aber nun nicht, wie bisher, bei einer „solipsistischen“ Betrachtungsweise stehenbleiben. Welt ist dementsprechend wesensmäßig eine Gemeinschaftswelt, in der das Ich mit Anderen existiert. ${ }^{29}$ Das transzendentale Ego als „transzendentaler Robinson“, wie es zunächst nach der Reduktion scheinen mag, ist eine Abstraktion. Welt ist immer schon Gemeinschaftswelt. Lebt das Ego in seinem faktischen Vollzug seine eigene transzendentale Historizität in Gemeinschaft mit anderen, so gilt für die Welt als intersubjektive das Analoge, sofern Welt immer geschichtlich gewordene Gemeinschaftswelt ist, in der sich Akte mannigfacher Subjekte ${ }^{30}$ sedimentiert haben, und auch das ist ein Wesensbefund: „Welt trägt eine wesensmäßige Historizität in sich: vor der Frage nach der faktischen Geschichte. “31 Dieses „In-sich-Tragen“ ist als Enthaltensein des Transzendentalen im Weltlichen zu interpretieren und zeigt erneut, daß es für Husserl zwischen beiden „Sphären“ keine Spaltung gibt, sondern daß sie die Momente einer Struktur darstellen. Wie Subjekte weltlich leben, ist Welt ihrerseits nicht nur geschichtlich, sondern bistorisch im Sinne der transzendentalen Betrachtungsweise. Die Historizität, von der hier die Rede ist, ist keine andere als die der transzendentalen Intersubjektivität, von der bisher lediglich ihre primordiale Stufe berücksichtigt worden ist. Das Verhältnis von transzendental und

28 Vgl. Hua XXXIV, 148 (sowie im Ganzen Text Nr. 8).

29 Das Wort „Welt“ stammt etymologisch vom mittelhochdeutschen weralt ab, was eine Zusammensetzung von wer (Mensch, vgl. lat. vir) und alt (Alter, Zeit, Lebenszeit) ist. Der Zusatz ,intersubjektiv“ zu Welt ist also strenggenommen, bereits dem Ursinn von „Welt“ entsprechend, tautologisch.

30 Bekanntlich spricht Husserl dann auch von Menschheitsgruppen als „Personalitäten höherer Ordnung“ als „Analogon einer einzelnen Person“ (Hua XV, 154, vgl. auch die ausführlichen Analysen hierzu in Hua XIV).

31 A VII 11/8b, von September/Oktober 1932. 
faktisch überträgt sich von Ego und „dessen“ Welt auf die Ego-Gemeinschaft und Welt selbst, insofern sie eine Welt gemeinsam fungierender (einschließlich fungiert habender und fungieren werdender) Subjekte ist. Aber dennoch gilt, daß dies eben nur vom primordialen Ich her zu enthüllen ist:

„Mein apodiktisches Faktum als transzendentales birgt in sich die apodiktisch in transzendentaler Zeitlichkeit seiende transzendentale monadische Subjektivität und ihr Sein in einer relativen Geschichtlichkeit, gegliedert in transzendentale ,Menschheiten'.“32

Hieraus folgt, wie Husserl in diesem Manuskript fortfährt:

„Die Welt ist ein historisches Gebilde meiner immanenten Zeitlichkeit in der mir transzendental implizierten Historizität meiner ,Menschheit', in der ich transzendental zeitlich selbst transzendental ,objektiviert' bin als Monade und als das eine sozial verbundene Koexistenz habe. Aber in eigener Art: Ich als transzendentales zeitloses monadisches Ich und meine transzendentale ,Menschheit ${ }^{\star}$ $\operatorname{sind}^{33}$ in historischer Entwicklung. ${ }^{34}$

In diesem Zitat ist mehreres bemerkenswert: Das transzendentale Ego wird zunächst als Monade bezeichnet, die „als das“ sozial verfaßt ist. Husserls Monaden haben also, wie man weiß, Fenster. Ferner hat das transzendentale Ego als „zeitloses“ Ich eine historische Entwicklung; dies deutet auf den oben erläuterten Wesensumstand hin, daß es zum Eidos Ego gehört, historisch zu sein. Schließlich: Die Fundierungsreihenfolge verläuft umgekehrt zu der der Entdekkung durch den Phänomenologen: Die Geschichte als faktisch verlaufende ist etwas, worin ich als faktisches Ich mit meiner „lebendigen Geschichte“ vorkomme. Die Weltgeschichte selbst ist wiederum die verweltlichte Form der transzendentalen Geschichte als Geschichte der transzendentalen Historie der transzendentalen Intersubjektivität bzw. des transzendentalen Monadenalls. Wie das faktische Ego in seiner Geschichte seine transzendentale Geschichte in sich „birgt“ (als „Index“ impliziert) als seine innere Sinngeschichte, so hat die faktische Geschichte der Welt ihre ihr vorhergehende (vorgegebene), sie konstituierende Sinngeschichte, die ihr nicht zeitlich vorhergeht wie etwa einem Akt ein Entschluß voranginge, sondern die ihre für die natürliche Einstellung verborgene Tiefendimension ausmacht, die also immer vorhanden, aber unthematisch

32 Ebd.

33 Ms. bin statt sind.

34 A VII 11/8b. Vgl. in diesem Sinne auch Lembeck: Gegenstand Geschichte. Op. cit. 231; es müsse, so Lembeck, gezeigt werden, „daß die Geschichte konstitutiv gründet in der transzendentalen Subjektivität, die ihrerseits aber stets als Mensch in der Welt auftritt“. Ergänzend hierzu Bermes: ,Welt‘. Op. cit. 196: „[Husserls] Forschungsvorhaben wird im Fortgang seiner Studien um eine $[\ldots]$ transzendentale Empiriohistoriographie erweitert. In diesem Projekt wird die transzendentale Subjektivität als eine sich historisch zeitigende aufweisbar - und zwar inkarniert in der personalen Kultur und ihrer Vernunftgeschichte.“ 
ist. Die transzendentale Geschichte geht der faktischen vielmehr logisch „vorher", nicht nur im Sinne einer wesensmäßigen Struktur, gemäß der sich die faktische Geschichte konkret abspielt. Sie ist auch die Geschichte der „transzendentalen Menschheit“ ,35 die sich verweltlicht findet und „zu sich kommt“ in einer über sich selbst reflektierenden, sich über sich selbst aufklärenden Personengruppe, d.h. die endlose Generationenfolge von Wissenschaftlern. Diese ist notwendig, soll dieses Wissen weltliche Form annehmen, was gleichbedeutend damit ist, daß das Wissen reflektierend bewußt wird in faktischen Menschen, die ihren beschränkten Horizont der natürlichen Einstellung verlassen, also zu transzendental reflektierenden Philosophen werden. D.h., die Rückfrage enthüllt Wesensstrukturen der Genesis, nicht etwa den Ablauf der Genesis selbst wie etwa ein geheimes „Drehbuch“, zu dem man auf mysteriöse Weise Zugang gewinnen könnte. Es ist also eine durch und durch rationale Aktivität reflektierender Menschen, die damit einen besonderen Rang innerhalb der Gesellschaft einnehmen (die Philosophen als „Funktionäre der Menschheit“).

Das weist auf die Wissenschaft und die Philosophie als Existenzformen des Menschen, in denen sich dieses zunächst verborgene Wissen realisiert oder manifestiert. Diese Monaden sind dann „erwacht“ anstelle von „schlafend“ in ihrem normalen Lebensvollzug in „natürlicher Einstellung“. Wie es eidetisch zu einem Ego gehört, sich selbst hinsichtlich seiner transzendentalen Dimension zu verhüllen, gehört es wesenhaft zu einer Menschengruppe, zunächst naiv zu sein, aber gewisse Individuen zu präfigurieren, die aus dieser Selbstvergessenheit ausbrechen können und dazu bestimmt sind, „der Menschheit die Augen öffnen“ und den „wahren Sinn der Welt zu entdecken“. ${ }^{36}$ Das weist auf die teleologische Dimension in Husserls Geschichtsphilosophie. Eine Menschheit - grundsätzlich eine Gruppe von Subjekten - kommt nur dadurch zu sich selbst, daß es Individuen gibt, die den gewöhnlichen, selbstverständlich hingenommenen Lebenshabitus durchbrechen. Und das Einzelego kommt nur zu sich selbst, wenn es, sich über die natürliche Einstellung erhebend, sich als Teil einer im Ganzen aufwärts strebenden Menschheit sieht, der es, selbstschaffend und aktiv, zugehört: „Weiter fortschreitend verstehe ich [als meditierender Philosoph], daß durch jedes transzendentale Dasein, aber nicht bloß einzeln, sondern in der intersubjektiven Vergemeinschaftung und als intersubjektive Totalität hindurchgeht ein Einheitsstreben der, Vervollkommnung'. Es ist kein Zufall, daß der Mensch, immerfort mit

$35 \mathrm{Zu}$ diesem Begriff vgl. Hua XXXIV, 153 ff., sowie vom Verf.: Husserl's Concept of the Transcendental Person. Op. cit., worin der Versuch unternommen wird, Husserls Rede von der "transzendentalen Person“ oder „transzendentalen Menschheit“ als v.a. gegen Heidggers Kritik ins Spiel gebrachten Begriff zu verstehen.

36 Vgl. Hua-Dok. II/1, 216 (aus Manuskripten im Zusammenhang mit Finks „Sechster Cartesianischer Meditation“ von 1934). 
Einzelheiten der Erfahrung, der Bewertung, der begehrenden und handelnden Abzielung (Bezweckung) beschäftigt, niemals zu einer Zufriedenheit kommt ..." ${ }^{\star 37}$

$\mathrm{Daß}$ das Transzendentale sich in der faktischen Geschichte verweltlicht, besagt dann, daß der „Sinn“ der Geschichte nicht außerhalb ihrer zu suchen ist weder in einer göttlichen Transzendenz noch in einer solipsistischen „Immanenz" -, sondern in ihr selbst liegt, wenn die Akte, die sie zustandegebracht haben, in ihrer transzendentalen Funktion enthüllt sind, sowie die Welt als konstituiertes Sinnprodukt und -ensemble. Der Verlauf der Geschichte als von Subjekten gestaltet selbst ist ihr Sinn, dessen sinn-volle Entwicklung allein durch Krisen gestört bzw. unterbrochen werden kann. Allein die transzendentale Betrachtungsweise kann diesen Sinn entdecken, sofern es sich bei diesem Sinn der Geschichte nicht um die res gestae bestimmter Menschheiten handelt, die man einfach nacherzählen könnte. Husserls Betrachtungsweise ermöglicht es vielmehr, die inneren Sinnmotivationen zu rekonstruieren, die erst so etwas wie eine faktische Entwicklung in ihrer kausalen Aufeinanderfolge ermöglichten.

Wie steht es nun mit der Aufgabe einer „Ontologie der Lebenswelt“ als Auslegung unserer gemeinschaftlichen Alltagswelt? Die Lebenswelt ist als Konstitutionsprodukt Ergebnis einer transzendentalen Sinnbildung, die als Genesis von Konstitutionsleistungen zu begreifen ist. Diese transzendentale Sinnbildung in genetischer Gesetzmäßigkeit ist nichts als die transzendentale Geschichte der Lebenswelt. Die Lebenswelt wird dadurch begreifbar als eine wesenhaft geschichtliche Welt und weist zurück auf ihre transzendentale Geschichte als „innere" Geschichte, die aber nicht ein anonymer Vorgang ist, sondern die Tat handelnder Subjekte. Dieses „Zurückweisen“ ist so zu verstehen, daß die Lebenswelt als faktische geschichtliche Welt diesen transzendentalen Horizont „in sich trägt“. Eine "unorthodoxe“ Art, dies zu formulieren, wäre zu sagen, daß Geschichte als faktischer Verlauf einer Menschheit vollends durchtränkt ist von Subjektivität, von Leistungen fungierender Akteure, und nicht ein geschichtlicher Verlauf ist, der - als „Seinsgeschick“ oder „Wirkungsgeschichte“ - als anonyme Macht einfach über uns kommt. Diese Sichtweise ruft die Menschheit radikal zurück in der Verantwortung ihrer selbst, ihrer Lebenswelt und ihrer Geschichte gegenüber. Das ist das Husserlsche Verständnis dessen, was „Aufklärung“ im Rahmen der transzendentalen Phänomenologie bedeuten kann.

Nach Einsicht in diese Wesenszusammenhänge drehen sich die Fundierungsverhältnisse um: Der transzendentale Horizont trägt als umfassender den faktischen Horizont „in sich“. Wie der Mensch nur als leiblich verfaßter und einzelner in der Welt vorkommt, so gibt es auch nur eine Welt, die aber als faktischgeschichtliche ihre transzendentale Geschichte realisiert, d.h. verweltlicht und als

37 Hua XV, 404 (aus einem Manuskript von 1931). 
solche erst „real“ macht. Erst die durch die phänomenologische Reduktion eröffnete transzendentale Dimension enthüllt die Lebenswelt als das, was sie im tiefsten Sinne ist, aber ohne transzendentale Rückfrage nicht erkannt werden kann. ${ }^{38}$ Die Lebenswelt ohne den transzendentalen Horizont, worin sie genetisch konstituiert wird, zu beschreiben, käme dem Versuch gleich, den Menschen als lediglich faktischen zu beschreiben und die Sphäre des Geistes zu naturalisieren, ohne ein Wissen von seiner transzendentalen Dimension: Man fiele in eine vorphilosophische Naivität zurück und betriebe lediglich Anthropologie (oder Soziologie oder Historiographie) als positive Wissenschaften, im gleichen Sinne, wie eine faktische Bewußtseinswissenschaft „nur“ Psychologie ist (etwa als „deskriptive“, selbst als eidetische) und nie Philosophie sein kann als Klärung von Gründen und Bedingungen von Möglichkeiten. In gleichem Sinne würde eine genetische Phänomenologie ohne transzendentalen Index nur Historiographie zufälliger Subjekte betreiben ohne eine Ahnung vom Sinn, der sich in der Geschichte ereignet, der aber selbst konstituiert und ein „Werden zum Sein“ ist. Man erreichte ebenso, wie man eine „Außenbetrachtung“ des Menschen als psychophysischen geben kann - und damit seine Eigentümlichkeit als Person gerade übersehen hätte -, eine Außenbetrachtung der Geschichte als kausaler Rekonstruktion der res gestae anstelle einer phänomenologischen Innenbetrachtung, die für Husserl die transzendental-philosophisch einzig angemessene ist. Eine solche „Außenbetrachtung“ wäre etwa eine Rekonstruktion einer „Wirkungsgeschichte“, die die Wirkung einer bestimmten kulturellen Formation rein als gegeben hinnimmt (als „klassisch“), anstatt die Innenperspektive einzunehmen und nach den Gründen, Motiven und Bedingungen zu fragen, die es ermöglichen, daß etwas in einer bestimmten Epoche und Menschheitsgruppe klassisch werden kann.

38 Den Zusammenhang von Lebenswelt und transzendentaler Subjektivität zeigt auch sehr schön Bermes, op. cit., z.B. 218. Bermes' durchgängige These ist, daß Welt bei Husserl zusammenhängt mit dem subjektiven Ichleben als ,utopisches, nicht standpunktgebundenes ,Ichleben“ in aktiven Vollzügen“ (ebd. 220). Vgl. auch ebd. 221: „Die transzendentale Subjektivität kann [...] jedoch in einem anderen Sinne als utopisch qualfiziert werden. Sie ist es nämlich, die sich in dem funktionalen Einstellen in ,Welt' ausdrückt und in diesem Prozeß, Welt' zu einem Thema ihrer selbst machen kann. Das transzendentale Subjekt ist dasjenige Subjekt, dem es in seinem Einstellen in Welt um Welt als einem Thema ihrer selbst geht." (Ebd., 221) Diese letztere Formulierung, die an Heideggers Formulierung hinsichtlich des Daseins, dem es „,in seinem Sein um dieses Sein selbst geht“", erinnert, macht deutlich, daß Welt und Subjektivität nurmehr Strukturmomente einer umfassenden Struktur sind, oder, in Heideggers Terminologie, „Welt“ ist auch bei Husserl nichts anderes als ein „Existential“ eines (nicht nur des spezifisch menschlichen) Subjekts, was aber nur durch die transzendentale Wende voll einsichtig werden kann. 


\section{Zusammenfassung}

Wie aus diesen letzten Andeutungen ersichtlich wird, stehen wir allerdings mit diesen Erörterungen nur am Anfang der eigentlichen Untersuchungen von der Konstitution der geschichtlichen Lebenswelt; sie geben aber den Rahmen vor, worin diese Analysen sich einordnen. Das „Koordinatensystem“, wie anfangs metaphorisch gesagt wurde, ist erst hiermit gezeichnet, was aber auch bedeutet, daß die konkreten und ausführlichen Beschreibungen, die Husserl im Zusammenhang mit der „Theorie der Weltapperzeption“"39 gegeben hat, erst hierdurch in ihrem systematischen Gehalt verständlich werden können. Wie hängen Faktizität und Geschichtlichkeit also systematisch zusammen im Rahmen der Ontologie der Lebenswelt? Zusammengefaßt läßt sich sagen: Alle Wissenschaft und diese Lebenswelt-Ontologie soll ja wissenschaftlichen Charakter haben - ist grundsätzlich Wissenschaft von der Welt. Sofern man im Rahmen von transzendentaler Phänomenologie von dieser Welt als Erfahrungswelt menschlichen, faktischen In-ihr-Lebens ausgeht (man könnte auch, wäre uns dies zugänglich, von Marsbewohnern und ihrer Welt ausgehen), ist sie auf ihre transzendentale Sinnkonstitution hin zu befragen. Die transzendentale Konstitutionsleistung terminiert aber in dieser faktischen Welt, bzw. ihre Faktizität ist verweltlichter, um sich selbst unwissender Modus der Transzendentalität. Faktizität heißt in diesem Zusammenhang also - neben dem Leiblich-Verfaßtsein - auch „unwissend um die transzendental-konstitutive Dimension“. Es gibt also nur eine Welt, die wesentlich ihre verborgene transzendentale Tiefendimension „,in sich trägt“, aber auch fortwährend „verweltlicht“, wobei die transzendentale Leistung von Sinn gleichzeitig fortwährend ,ihre Spuren verwischt“. In diesem Sinne könnte man sagen, daß die Welt selbst das Absolute ist, sofern transzendentales Leben und Lebenswelt die Momente einer Struktur sind. Dieser „Finksche“ Kniff ist also bereits bei Husserl vorgezeichnet, auch wenn Husserl den Begriff „Absolutes" für das konstituierende Bewußtsein reservierte. ${ }^{40}$ Aber das ist ein reiner Wortstreit. Die Sinnkonstitution der Lebenswelt ist nun Ergebnis einer Genesis oder Geschichte im transzendentalen Sinn, als innerer Geschichte des transzendentalen Monadenalls, das eine transzendentale Historizität in sich birgt und diese und sich selbst im konstitutiven Prozeß fortwährend verweltlicht (und damit immer auch zunächst verhüllt). Damit ist die genetische Dimension in die Lebenswelttheorie unwiderruflich eingeschrieben. Der ontologische Status der transzendentalen Menschheit aber ist - zumindest in dieser Hinsicht - so aufzu-

39 Dies ist der Husserlsche Titel der A VII-Gruppe in Husserls Nachlaß, worin er den Großteil seiner Texte zur Analyse der Lebenswelt versammelt hat.

40 Vgl. jedoch schon Husserls Rede vom Absoluten als „absolutem Faktum“, Hua XV, 403 (von 1931): „Das Absolute, das wir enthüllen, ist absolute, Tatsache. “" 
fassen, daß sie sich stets als faktische verweltlicht findet in einer Welt, die geschichtlichen Charakter hat „dank“ der transzendentalen Geschichte der agierenden Subjekte in ihr. Nur so ist ihre Faktizität zu verstehen, als ständig verweltlichtes transzendentales Sinngeschehen. Geschichtlichkeit und Faktizität im so explizierten Sinn gehören also notwendig zusammen als die beiden Achsen, in die sich die Ontologie der Lebenswelt „einträgt“.

Am Ende der Überlegungen aus dem zitierten Manuskript A VII $11^{41}$ notiert sich Husserl: „Das ist die Phänomenologie, die von der vorgegebenen Welt zurückführend weltliche Historizität als Gebilde der transzendentalen Historizität entdeckt und nun statt der naiv konstituierten menschlichen Welt die ihr gegenüber absolute Monadenwelt als in ihrer historischen Allzeitlichkeit seiende, sich fortentwickelnde, sich selbst gestaltende und in sich ständig als objektivierende Welt gestaltet, mit weltlichen Menschen und Tieren, die weltlichen Menschen als menschliche, als menschliche Selbstgestaltung als willentlich in sich ausbildend. “42

Die Reflexionen in diesem Manuskript enden mit der Feststellung: „Damit ist aber Phänomenologie nicht zu Ende. “43 Im Gegenteil, im Sinne der noch zu leistenden analytisch-deskriptiven Arbeit steht sie gerade erst am Anfang. Es bedarf allerdings, wie darüber hinaus angedeutet wurde, einer in gewissem Sinn entwickelten Menschheit, die diese Zusammenhänge enthüllen kann, die sich damit erst zur „wahren Menschheit“ erhebt, indem sie die naive Stufe überwindet und einem idealiter antizipierten Ziel entgegenstrebt, das sie durch diese Reflexion erkannt hat. Der Anfang zu diesem neuen Aufbruch kommt also erst am relativen Endpunkt einer langen Entwicklung, die einen neuen Anfang ermöglicht. So deutet sich an, daß man in diesem Zusammenhang ein anderes, hiermit untrennbar verwandtes Thema, das Husserl v.a. in seiner letzten Phase intensiv beschäftigt hat, für die weitere Analyse zu berücksichtigen hätte, nämlich das Problem der Teleologie, was jedoch hier nicht mehr Thema sein kann. Aber wie Husserl andeutet, ist eine Teleologie der wissenschaftlichen Vernunftmenschheit ohne vorhergehende „transzendentale Archäologie“ nicht durchführbar. Wie

41 Das 69 Blätter umfassende Manuskript scheint im Ganzen aus dem Oktober $1932 \mathrm{zu}$ stammen. Es trägt folgende Inhaltszusammenfassung auf dem Umschlagblatt 1a: „Problem der Weltanschauung. Möglichkeit einer Ontologie. Seiendes - in der Welt als Universum, bezogen auf die Universalität fungierender Subjektivität. Überhaupt über Sein. Kritik der naiven ,klassischen' Idee von Seiendem etc. Sein und adäquate Wahrnehmung. ,Evidenz der inneren, Nichtevidenz der äußeren Wahrnehmung'. Reine Erfahrung. Klassische Idee des Seienden und Wissenschaft." Teile dieses Manuskripts werden in der Husserliana im Rahmen einer Edition zu Husserls späten Texten zur Konstitution der Lebenswelt zur Veröffentlichung gelangen.

42 A VII 11/11a.

43 Ebd. 
eine solche „Archäologie“ ihrerseits zu verstehen ist, sollte hier rekonstruiert werden.

Was Husserl mit „transzendentaler Geschichte“ und Lebenswelt meint, wird hierdurch im Umriß verständlich, macht aber auch den hochkomplexen, letztlich eventuell sogar problematischen Charakter von Husserls Rede vom „transzendentalen Leben" und seinem Verhältnis zur Faktizität in seiner letzten Arbeitsperiode in aller Schärfe deutlich. Was Husserl damit gemeint hat, daß Transzendentales und Faktisches anscheinend „Momente“ einer Struktur sind, muß also auch weiterhin Thema philosophischer Bemühungen sein, die sich jedoch vom Husserlschen Jargon zu lösen bemühen muß (was hier nur im Ansatz geleistet werden konnte). Die vorstehenden Bemerkungen hatten den Zweck, Husserls späte Lebensweltphilosophie in ihrer Komplexität, aber auch ihrem vollen Abstraktionsgrad deutlich werden zu lassen. Wie deutlich geworden ist, war Husserl bis zuletzt damit beschäftigt, seine systematische Phänomenologie, als systematische Methode, auszugestalten. Die Endgestalt von Husserls Denken wird damit sicherlich nicht leichter verständlich, aber in ihrem Reichtum sichtbar, der noch kaum ausgeschöpft ist. Die „offenen Horizonte“, von denen Husserl hinsichtlich der Phänomenologie als „Arbeitsphilosophie“ sprach, sind damit keine hohle Phrase, sondern Aufgabe für die Zukunft einer Denkbemühung, die die konkrete Faktizität und die Geschichtlichkeit des menschlichen Lebens ernst nimmt. Ob damit die Spezies Mensch das von Husserl antizipierte Telos einer vollaufgeklärten Vernunftmenschheit je wird erlangen können, ist dennoch heute fraglicher denn je. ${ }^{44}$

${ }^{4}$ Ich danke dem Direktor des Husserl-Archivs in Löwen, Prof. Dr. Rudolf Bernet, für die Genehmigung, aus Husserls unveröffentlichten Schriften zu zitieren, sowie Rochus Sowa (Löwen) für den Hinweis auf einige Passagen v.a. aus der A VII-Sektion des Nachlasses. Ferner danke ich Prof. Dr. Karl-Heinz Lembeck für hilfreiche Verbesserungsvorschläge zu einer früheren Version dieses Textes. 